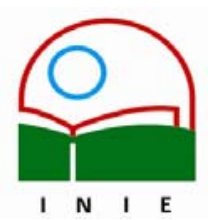

Universidad de Costa Rica

Facultad de Educación

Instituto de Investigación en Educación

ACTUALIDADES INVESTIGATIVAS EN EDUCACION

\title{
WEB-BASED LEARNING (WBL): A CHALLENGE FOR FOREIGN LANGUAGE TEACHERS
}

\section{Allen Quesada Pacheco'}

\begin{abstract}
Net-work based language teaching does not represent a particular technique, method, or approach. It is a constellation of ways by which students communicate via computer networks and interpret and construct online texts and multimedia documents, all as part of a process steadily increasing engagement in new discourse communities
\end{abstract}

(Warschauer \& Kern, 2005, p. 17)

Resumen: En las últimas dos décadas se ha realizado una amplia gama de investigaciones sobre el uso de las computadores a nivel educativo con un enfoque hacia la adquisición y retención del conocimiento. Este artículo investiga temas claves sobre la eficacia, actitud y desarrollo de los cursos en línea. La terminología para describir este tipo de educación se conoce como instrucción mediada por Internet. El marco teórico de este artículo examina la evolución de la enseñanza por medio de Internet hacia una metodología integrada que dirige la enseñanza de un idioma con acceso al Internet. Se describen las características de la Instrucción por medio del Internet y como este tipo de Instrucción da soporte para la adquisición de la comprensión auditiva, la comunicación oral, la lectura comprensiva y la redacción. Se hace énfasis muy particular en la relación de la Instrucción en Línea y el desarrollo de autenticidad por medio del Internet.

Palabras clave: APRENDIZAJE DE IDIOMAS MEDIADO POR LA COMPUTADORA/ APRENDIZAJE MEDIADO POR LA INTERNET/ LA WEB/ APRENDIZAJE Y ENSEÑANZA DEL INGLÉS MEDIADO POR INTERNET/

Abstract: The vast majority of research in the past two decades on the use of computers in education has focused on knowledge acquisition and retention. The focus of this article is to investigate the issues of self-efficacy, attitude, and performance in online courses. Web-based learning will be the term used to describe this type of computer use. The review of literature inquires into the evolution of Computer-Assisted Language Learning towards an integrative approach that leads to Web-based learning. The benefits, components and challenges of Web-based Learning are addressed as well as how this type of approachexploits authentic practice of listening, speaking, reading and writing. This article also probes the relationship Web-based learning and achieving authenticity through the World Wide Web.

Key words: COMPUTER-ASSISTED LANGUAGE LEARNING (CALL)/ WEB-BASED LEARNING (WBL)/ ASYNCHRONOUS COMPUTER-MEDIATED COMMUNICATION/ SYNCHRONOUS COMPUTER-MEDIATED COMMUNICATION/ WORLD WIDE WEB (WWW)/

\footnotetext{
1 Doctor of Philosophy in Curriculum and Instruction (Enseñanza del Inglés), University of Kansas (KU), E.E.U.U. Master of Arts in TESOL, NewYork University. Master of Science in Educational Technology, University of Kansas. Catedrático, docente e investigador. Vice-Decano de la Facultad de Letras de la Universidad de Costa Rica. Coordinador de la Comisión de Autoevaluación y Acreditación, Escuela de Lenguas Modernas.
}

Correo electrónico: allenq@cariari.ucr.ac.cr

Artículo recibido: 6 de julio, 2005

Aprobado: 31 de octubre, 2005 


\section{Introduction}

Computer-assisted language learning (CALL) is reaching an up most position in the pedagogical field of English as a Second or Foreign Language (ESL/EFL). Its powerful presence has fostered learner autonomy and a wide range of opportunities for authentic interaction in the target language (English) in computer-based conditions. Web-based learning is becoming an even more powerful interactive source that increases learners' knowledge and that guarantees quantity and quality of language input and output. Added to this, the changing role of the teacher is more responsive to students' self directed learning: that of teaching learners how to learn, stimulating learners to do by themselves, and acknowledging learners of their commitment for self-motivated opportunities to use the language for authentic communicative purposes. This paper examines the impact web-based learning has in the acquisition of English, delineates benefits, challenges and guidelines for both teachers and students, and addresses issues towards an integrative approach to using technology (web-mediated learning) for the acquisition of listening, speaking, reading and writing.

\section{CALL and Web-based learning (WBL)}

Computer technology has become a state-of-the art component in second and foreign language classrooms. CALL resources have supplemented English teaching in authenticity (vast amounts of authentic materials are experienced by the learner), literacy (students master skills such as reading, writing, communicating, researching and publishing for academic and occupational goals), interaction (meaningful communication with native and non-native speakers worldwide), vitality (ESL/EFL learners are boosted in their motivational needs to communicate with freedom, flexibility, and real time without engaging in memorization of grammar rules), and empowerment (learners become autonomous collaborative learners, and teachers, coaches that teach how to learn/how to construct new knowledge). Warschauer, Shetzer and Meloni (2002) have explained that computer technology help ESL/EFL classrooms come ALIVE (Authenticity, Literacy, Interaction, Vitality, Empowerment).

Computer-Assisted Language Learning has indeed influenced education throughout the years. That is why CALL has developed from a traditionally self-contained, programmed type of application where learners where exposed to tutorials, drills, simulations, instructional games, tests, and controlled practices to a more human-to-human communication type of application where learners can potentially communicate with native speakers or any other 
language learner all over the world on a one-to-one basis or many-to-many basis without restrictions of time or place with access to the Internet (Kern \& Warschauer, 2005). By understanding the development of CALL, we can understand the innovative applications of CALL.

\section{Development of CALL}

Moras (2001) has divided CALL into three distinct phases: behaviorist, communicative and integrative: Behaviorist CALL was implemented when the Audio-lingual Method was popular (around the 1960's and '70) and it viewed the computer as a tutor which presented drills and non-judgmental feedback to practices. The "programs were designed to provide immediate positive or negative feedback to learners on the formal accuracy of their responses" (Warschauer \& Kern, 2005, p. 8). The disadvantage of this structural approach to CALL were several: it provided little excitement among teachers and learners, only one possible response was acceptable, and repeated drilling on the same material was the objective of the programs (Warschauer \& Kern, 2005).

As the communicative approach gained recognition, around the 80's and 90's, communicative CALL arose, focusing more on using forms or structures of the English language rather than on the forms themselves. There was a shift from the drilling format to skill practice through games, reading and text construction (Moras, 2001). Thus, Moras expanded, the computer continued being a tutor, but was also used as a stimulus and as a tool. It served as a stimulus when learners were involved in programs that stimulated writing or discussions, not specifically designed for language learners, and as a tool, in programs that did not provide language material, but that enabled the learner to understand and use the language such as word processors, desk-top publishing, spelling and grammar check programs when learners were engaged in process writing. According to Warschauer \& Kern (2005), the advantage of this cognitive/constructivist (communicative) approaches to CALL was that learners could construct new knowledge from their existing knowledge through exploration, problem solving, and hypothesis testing. This process allowed learners to develop new understandings and to do something with these in a stimulated environment. Even though there was a change to more active CALL opportunities for communication, genuine negotiation of meaning was not accomplished. It was still a closed system.

Sociocognitive or integrative CALL, ultimately has revolutionized communication making it more authentic and meaningful. Learners no longer interact with computers but with other humans with the computer as a tool or resource. Warschauer and Kern (2005, 
p.11) have highlighted the theoretical and technological developments for this new approach to CALL: "Theoretically, there has been the broader emphasis on meaningful interaction in authentic discourse communities. Technologically, there has been the development of computer-networking, which allows the computer to be used as a vehicle for interactive human communication". Review of the literature for many years has argued that all human learning is mediated through interaction with others because we live in social contexts and as individuals grow up and move to the different stages of learning, social interaction is essential. This happens in first and second language learning. CALL facilitates this process through computer-networking. The access is not only to people but to authentic information and data that is part of the growth of society.

But, what is computer networking? Warschauer and Kern (2005) have explained that computer networking in language classrooms can be categorized into two important technological and thus, interactive developments: one related to computer-mediated communication (CMC), and the other one related to globally linked hypertexts, both of which provide different ways for communicating and exchanging information. These features can be seen clearly as follows:

a. Asynchronous computer-mediated communication: This networking means of communication is the one that is usually done through electronic mail (e-mail), in a delayed fashion, where individuals send or receive messages, and do not need to be sitting in front of the computer all the time. Through electronic mail, learners also have the opportunity to share information such as word-processed documents, sound files, pictures, computer software, and even full-motion pictures as attachments. There are many ways to do this: on-to-one basis, or on-to-many basis, or many-to-many basis by being part of e-mail discussion groups (Warschauer, Shetzer, \& Meloni, 2002).

b. Synchronous computer-mediated communication: This is real-time networking communication. In other words, messages are received and sent instantly, as if individuals were having a telephone conversation. This interaction occurs on-line, and can be either written down (text) or can occur through audio and video. This way of communication is called chatting, and can happen in a one-to-one basis or many-tomany, as in internet-based chat rooms. (Warschauer, Shetzer, \& Meloni, 2002

c. Globally linked hypertexts: It is referred to as the World Wide Web (WWW). By using the World Wide Web, students can search through millions of files around the world within minutes to locate and access authentic materials (newspaper and magazine articles, research, radio broadcasts, movie reviews, reports, newsletters, software, web- 
publishing sites, among many others). The resources of the World Wide Web are unlimited, and the advantages it provides for language learners are tremendous. For example, students can publish their texts or multimedia materials, and these can be shared with partners or any other individual around the world (Warschauer \& Kern, 2005).

This new approach to CALL, Integrative CALL, can only reach its goal of providing authentic means of communication if learners are exposed to this technology responsibly. Learners will not achieve levels of communicative competence by just having them use a computer. As any language class, the use of networking processes for learning a second or foreign language should be well-planned taking into consideration many different variables: students' interests, students individual styles and strategies of learning, students' needs, lacks, and wants as well as the goals of the lesson, the content, the resources. Likewise, both the roles of the students and teachers will change into "learning how to learn" (autonomous learners) and "teaching how to learn" (coach). At the end, a well-planned class is what will make the difference and using a computer will foster that difference. But, how can a wellplanned class be integrated with computer use? Web-based learning is what will make the difference.

\section{Features of Web-based Learning (WBL).}

The Internet is providing a new powerful, flexible, and efficient tool for technologyenhanced learning. Online education or through the World Wide Web (WWW or Web) has become a prominent feature of CALL and is also considered as the easiest and the most popular approach to higher education because of advanced computer technology. This new trend is called Web-based Learning.

Scholars have defined WBL as "a hypermedia-based educational program which utilizes the attributes and resources of the World Wide Web to create a meaningful learning environment where learning is fostered and supported" (Khan, 1997); "the application of a repertoire of cognitively oriented instructional strategies with a constructivist and collaborative language learning environment, utilizing the attributes and resources of the World Wide Web" (Relan \& Gillami (1997); "individualized instruction delivered over public or private computer networks and displayed by a Web browser (Clark, 1996) (cited in Henke, 1997, p.1). All of these definitions have a common feature: Internet or the World Wide Web. From a pedagogical perspective, WBL provides an added value to the learning of languages. It supports the shift from the traditional teacher-centered classroom to a learner-centered 
environment. Learners are encouraged to learn by themselves and are motivated to continue in the growth of their own learning when connected to others. WBL provides benefits in the accessibility and availability of authentic materials, too.

Maddux (1996) has stated that some unique characteristics of the Web include: (a) information on the WWW can be made interactive in nature; and (b) it often makes use of multimedia, including graphics, sound, and animation. The Web provides more effective and efficient searching tools than traditional searches in libraries, and the pages retrieved from the web are more attractive and appealing than traditional printed media. Moreover, multimedia capabilities probably make the Web more attractive to many people.

In terms of pedagogical features of the Web, WBL facilitates communication, enhances interactions, provides student-centered, self-paced, and collaborative learning, disseminates shared information, and reaches out to global communities (Downing \& Rath, 1997; Maddux, 1996; Chellappa, et al, 1997). Research studies also indicate that the long-term effects of learning via computers encourages student interaction and involvement in the whole learning process (Owston, 1997; Chiou, 1995; Gallini and Helman, 1995). McCarthy and Grabowski (1999) have also stated that incorporating Web-based lessons and activities is a new way for teachers to utilize computer technology to enhance learning. So, it seems that the Web encourages another new way that students prefer to use to learn. Therefore, more and more educators have experimented with the WWW sites for learning in order to make their teaching more attractive to and more interactive with students.

\subsection{Advantages of Web-based learning}

Dearing (1998), in The Report of the National Committee of Inquiry into Higher Education, pointed out that through Internet networks it is possible to offer different forms of contact and access to many highly effective learning materials that were previously unavailable to many students. He went on to discuss some of the benefits that communication and information technologies bring to learning and teaching in higher education:

One of the benefits of new technology lies in providing a learning environment that help learners succeed in improving understanding where other methods have failed. Computerbased programs, such as tutorials, simulations, exercises, learning tools and educational games, according to Dearing, are highly interactive and provide activities that students need, to develop their understanding of other's ideas and the articulation of their own. 
Basically, web-based learning environments are designed to offer more variety in features related to network information retrieval systems, electronic communication (e-mail), up-to-date course resources, interaction via newsgroups or forums (online discussion groups), multimedia lecture presentations, and course management than traditional classroom instruction (Collis, 1999). Thus, the Web has made people rethink the nature of teaching, learning, and schooling. That is why more and more institutions of higher education are beginning to use the Web to offer accredited courses or distance learners. The student can study independently online, communicate with the facilitator/coach, submit assignments, have access to course guides electronically from course web sites, and communicate real time (synchronously) with teachers and classmates for questions and discussions in chatting rooms. Owston (1997) has observed that the Web can also provide flexibility in teaching and learning, free from the physical boundaries of classrooms and the time restraints of class schedules. Added to this, lectures and demonstrations are possible through Web-based multimedia learning experiences for students (net meetings, conferencing). There is no doubt that learning resources of colleges and universities can be increased and/or shared via the World-Wide-Web (WWW) and educators in different institutions will finally shift their focus from teaching to learning, from teacher to student. In other words, teachers will give more responsibilities to learners as monitoring their own learning. Berge (2000) has highlighted the changing roles of teachers that emerge in online learning: teachers' role changing from lecturer and instructor to consultant, guide, coach and resource provider; teachers that become expert questioners, rather than providers of answers; teachers that provide structure to student work, encouraging self-direction; a shift of teachers from total control of the teaching environment to sharing with the student as fellow learner. In short, according to Berge, teacher-learner hierarchy is broken down.

From the learners' perspective, one of the significant advantages of Web-based learning is that the universal language that is manipulated by internet users is English, and that is the language they are willing to learn by all means. This aspect intrinsically motivates learners to access Internet sources or use Internet means because it provides authentic use of the English language, so learners see a usefulness in this resource. Many of the sites they can access are directed to the practicing of grammar, reading, pronunciation, vocabulary, listening, etc. What attracts their attention the most is that there are no limits in retrieving and practicing these different web-links over and over again, promoting learner independence and the development of learning strategies. The Web also enhances learning environments as well as interactive environments to shy students who do not dare to speak in class, but that 
are willing to chat real time with other students around the world. And how about the communicative skills students acquire through the web? Students have opportunities of negotiating, persuading, clarifying meaning, requesting for information, exchanging ideas, discussing, asking questions, etc. (Moras, 2001). Likewise, Berge (2000) posed challenging roles to learners: a change from students acting as passive receptacles to students who are constructing their own knowledge; a type of student who put hands into complex problemsolving activities rather than just memorizing facts; an increased role of collaborative/cooperative group members and teamwork in online classrooms; a shifting role towards autonomous, independent, self-motivated managers of their time; a role that makes emphasis on knowledge use rather than only the observation of the teacher's expert performance.

Another one of the primary advantages of the Web use is that it is attractive to students and uses a method students now prefer for learning. Papert (1993) has called the computer the student's machine because students in public schools and in colleges and universities have been using computers in the past decade, and they are really part of their lives. They can not live without them. Owston (1997) has stated that students who play and learn with computers, tend to be more interactive with computer technology and are more visual learners than previous generations because their world is full of visual stimuli. The WWW is a very unique way of linking text, images, sound, and video resources on computers connected with the Internet, and it is much more interesting to experience a conversation with live audio and video than simulating un-real conversations in class.

An innovation in WBL is incorporating interactive language-in-use projects which have Information and Communication Technologies (ICT or teaching and learning with the use of computer technology) as the key element in the teaching process. Dooly $(2005$, p. 8$)$ has clarified that "innovative uses of the Internet and other ITC tools provide opportunities for collaborative language projects which focus on using the language to learn the language". International collaborative projects provide wider opportunities for students to contact and communicate with other individuals outside their own country, incorporating intercultural knowledge, awareness, and communication skills as goals to be achieved during the project. Through this new learning approach, students are able to observe, identify, and recognize elements of their own and other cultures, compare and contrast, negotiate meaning, tolerate ambiguity, effectively interpret messages, limit the possibilities of misinterpretation, defend one's point of view while acknowledging the legitimacy of others' and have the ability to 
accept differences among individuals (Dooly, 2005). And most importantly, the gap of teaching culture in class is narrowed because learners can experience culture on line.

\subsection{Disadvantages of Web-based learning}

Despite the advantages, some arguments related to Computer-Assisted Language Learning (Web-based learning) are still in debate. As indicated by Krendl and Broihier (1992, p. 225), "as the technology gains a stronger foothold on our educational institutions and becomes a standard educational tool in the classroom, as well as a fundamental component of cultural literacy, it is critical that we understand students' response to this medium". Some have argued that the Web is simply a learning tool, and that this resource does not have a major effect on academic achievement of students if it is only used as a vehicle to search for and retrieve information Owston, 1997). Other studies on computer-based learning (the behaviorist trend) developed in the ' 80 s have indicated that this kind of instruction had simply computerized methods of programmed instruction without adding any value from using the computer. Obviously, there is no reason to expect the quality of learning to improve if educators just simply transfer a learning experience from one medium to another (Alexander, 1995). A study from Russell (1999) also reported that many of the 355 studies had shown no significant grade difference between face-to-face classes and computer-based learning or/and similar televised courses. Moersch (1998), on the other hand, stated that in their enthusiasm for web-delivered courses, many teachers have made technology an essential tool in their classrooms, perhaps putting too much emphasis on computers, and less emphasis on learner thinking that results from interacting with media (Jonassen, Campell, \& Davison, 1994; Morrisson, 1994; Kozma, 1944; Clark, 1994; Tennyson, 1994).

Besides, there are some constraints frequently encountered in synchronous interaction that coaches and resource providers may need to consider in terms of their impact on student learning through the Web. The constraints include a heavy reliance on text, lack of social interaction available to the instructor and students, time lags between questions sent to the coach/facilitator, and answers received by the students, and the solitary nature of the learning process for the student (Russo, 1999). Russo has pointed out that much of web-based courses consists of text only, a lean medium, although audio as well as video is being integrated more and more. She went on to state that Web-based courses are fundamentally unlike face-to-face classes and it is appropriate for researchers to ask whether the communication, learning processes, and outcomes involved in on-line courses would show no 
significant difference from face-to-face classes. Unfortunately, few studies in distance or online education focus on analysis of communication and learning processes in these contexts.

Another concern is that new users might quickly be discouraged because of technical difficulties such as access problems. Students using computers on campus can download the multimedia material very quickly. They also can rely on computer technical experts to deal with system crashes and other bugs. Off-campus, however, the situation is much less satisfactory because of low speed connections and the unavailability of technical help. So far, there is little research in distance or online courses regarding the relationships between communication and the learning process in these contexts.

Moras (2001) has identified that other disadvantages like lack of training and familiarity with computers and the Internet (by both teachers and learners) could lead to frustration, instead of motivation. Added to this, the Internet provides such an enormous quantity of information that adequate guidance to access specific websites should be provided, because the user would see the World Wide Web as a challenge rather than as a facilitating tool for learning. Moras has made emphasis on how teachers use this resource. Pedagogically, "the use of computers does not constitute a method. Rather it is a medium in which a variety of methods, approaches and pedagogical philosophies may be implemented" (Warschauer, 1996, cited in Moras, p. 3).

That is why the development of a web-based course should consider certain components for its appropriate use. The important thing to keep in mind, however, is that the greatest potential of Web-based learning is that educators have a chance to learn from previous experiences, and have opportunities to develop new learning experience for students which have not been possible before.

\subsection{Basic components of a Web-based course}

A well-designed course should contain pedagogical components to ensure its effectiveness. The same thing happens in a web-based course. It is grounded in pedagogical theories emphasizing "inquiry-based", "active", or "problem-solving" learning, where learning materials are developed in the active analyses, synthesis and evaluation of information (Edelson, Pea \& Gordon, 1999). A good web course design will take advantage of technology to make learning more responsive, relevant, and meaningful to students, allowing spontaneous experiences without physical distance constraints (Lan, 1999). Also, a good web course should be constructed to reflect the shift from an instructor-centered approach to a student-centered approach (Grunet, 1997). The following are considered to be major 
components in the construction of an effective web-based learning course (Polyson, Saltzberg, \& Godwin-Jones, 1996; Anderson and Joerg, 1996; McCarthy, Grabowski, and Koszalka, 1999; Lan, 1999).

1. General information. The online syllabus should include course descriptions and prerequisites, time, technical help and the coach's/facilitator's contact information (phone, fax, and email). It is very important that students know how and when the coach an be reached. Information about required technology tools, such as the Internet browser, plug-in programs, and how to use the course website should be included.

2. Course information. A web-based course should contain complete course descriptions, including course and unit objectives (general and specific), credit hours, activities, etc.

3. Schedule. It can also be referred to as a calendar. This component provides a timeline for the sequence of topics and activities in each session. It may include class requirements, content to be covered in each session, activities, assignments, exams, and surveys to be completed by students. This part probably includes the most important information for students.

4. Resources. This component provides all supportive and related course material. It includes the suggested text references and hyperlinks that the facilitator may choose to use to scan the documents directly into the course website. Web materials allow for easy updating and always provide up-to-date information for students.

5. Multimedia presentation of content. Perhaps the most difficult part of developing a webbased course is creating online content. The coach/resource provider can begin by transferring basic lecture materials, including lecture notes and summaries to the Web and integrating media such as sound, image, and video. This can make online learning more attractive and accommodate different learning styles of students.

6. The virtual classroom. Adding discussion forums, chat rooms, and e-mail to the online course is a common way to enhance interaction among students and the coach/facilitator. Class members can access and participate in asynchronized discussion as well as engaging in collaborative or private interactions as if they were in a real classroom. The coach/facilitator should use these functions, and communicate requirements to students. Discussion topics may be assigned to focus on course materials. Participation points may be assigned as part of a course grade in order to encourage students' participation. 
7. Assessments. This component should include the criteria that will be used to determine course grade. It may include a performance progress tracking system accessible to students via online. Students can check the individual progress for each session. The database of tracking student progress and grades is useful to the coach/facilitator or course management.

8. Testing. Online drill or practice tests can be used to reinforce learning. For example, short essay or multiple choice test formats can be used by students to provide a selfassessment of their level of understanding of the text.

Without these components, WBL s useless, especially when the ones that will be affected are precisely the students who want to learn a new language. To contribute in students' growth in the language, there are ways to support the acquisition of the four skills through WBL.

\section{Integrated language skills through Web-based learning}

One of the limitations ESL/EFL students encounter when learning English is inaccessibility to opportunities for practicing listening, speaking, reading and writing as well as grammar which is sometimes their main concern. There is no doubt that on-line courses provide ample opportunities for training students on these skills. However, it is also true that when these skills are learned and practiced in classes, they can be supported on-line by providing supplementary authentic materials which are not experienced in class. Many educational and linguistic goals are accomplished with this web-based support materials such as, active and creative mastery of skills, collaborative learning, autonomous learning, crosscultural learning and critical learning (Warschauer, Shetzer \& Meloni, 2002).

\subsection{Listening and speaking}

In order to speak and listen to English as a Second or Foreign language, learners need to use language functions such as sharing personal information, greeting, questioning, informing, clarifying, negotiating meaning, asking for clarification, agreeing/disagreeing, giving opinions, among others. To be communicatively competence, learners also need mastery in pronunciation, stress, rhythm, non-verbal communication, etc. To help learners acquire these skills, teachers engage learners in a series of communicative activities such as role-playing, simulations, games, scenarios, information-gap activities, singing, just to mention a few. 
There's a belief, however, that these skills are impossible to accomplish through web-based courses, mainly because listening and speaking are active skills. The WWW can truly activate listening and speaking, around the computer and through the computer.

Egbert (2005) has explained ways in which learners can listen and speak around the computer. Through the WWW, there is a wide range of listening exercises, starting with listening web sites, and incorporating listening to news stories ( National Public Radio site: http://www.npr.org). Some of these listening websites are The Internet TESL Journal, Renata's ESL/CALL Corner or Dave's ESL Café. Another website that helps learners in speaking to improve pronunciation and spoken grammar is Adam Rado's English Learning Fun Site (ELFS): http://www.elfs.com/). All of these websites mainly help learners acquire pragmatic skills, and self- assessment skills. Learners can share experiences with other learners on what they have practiced and notice if they have understood. Teachers should then engage learners in additional practices after they have worked around the computer to help them apply what they learned, and reinforce and understand the knowledge acquired to enrich their listening and speaking skills. When learners practice listening and speaking skills through the computer, on the other hand, meaningful interaction takes place. The computer becomes a means for direct communication with native speakers and more advanced speakers of the language, allowing ESL/EFL learners engage in synchronous and asynchronous conversations. Egbert (2005) has suggested the following activities:

a. activities using both synchronous and asynchronous audio exchanges that include audio dialogue journals in which two or more participants record messages and send them to each other in a running stream of conversation

b. activities involving students in the recording of audio segments in presentation software such as Power Point or trading suggestions (orally) for essay revision in versions of Microsoft Word that have audio commenting capabilities

This means that chatting is not the only means for practicing listening and speaking. There are other opportunities in safe atmosphere that allow learners to achieve up most mastery and practice.

A sample on-line lesson, as the following, allows learners to engage in debate and practice speaking functions such as the use of argument skills, discussion skills, critical thinking skills, formulating opinions, asking for clarification, agreeing and disagreeing. This on-line debate (comparing the Mentawai culture with their own culture, for example) is structured as follows: focus (skills/functions: discussing, comparing, etc), preparation (steps/procedure before online activity), presentation (debate itself/online and with video), 
practice (speaking stage/formulation of arguments/chat tool), evaluation (selfassessment/peer-assessment on arguments), and extension (entries for oral journal). The focus should be established first. Then, in the preparation stage, brainstorming is involved on the topic, and reflection activities when both cultures are compared. Teachers need to prepare materials in class to ensure understanding. During the presentation stage, students access the website assigned, and read about that culture, learn about it, discuss about it, learn vocabulary and pronunciation, and finally watch the video on-line. When they get to the practice stage, and chat real time, and discuss, much of the information was discussed in class already in the presentation stage so they are now prepared to interact and defend their arguments. At the end, during the evaluation stage, learners discuss together what they have learned and present their arguments to the class for additional practice. The extension activity allows them to reflect on how the debate impacted their ideas about their culture, as a reflective stage (Egbert, 2005).

This sample on-line lesson tells us that class time and CALL time are valuable and can work together in order to help learners achieve both competence and performance for listening and speaking.

\subsection{Reading and writing}

Just as listening and speaking, achieving reading and writing skills include mastery of specific skills like summarizing, understanding the main point, identifying organization (for both reading and writing), evaluating support arguments, predicting, drawing conclusions, organizing content, developing writing skills (content, organization, word choice, etc.), among others.

Web-based learning supports the acquisition of these abilities through "skills tools". Egbert (2005) has clarified that skills tools are "media-rich examples and integrate effective scaffolding to help learners understand and retain skills" (2005, p.22). AlKahtani (1999) has also exemplified the usefulness of computers to support reading and writing abilities as well as the grammar involved in these skills:

They can check exercises after they are done, move students gradually from easier to more difficult exercises according to their levels and abilities. When students fail to answer correctly or perform activities, the computer can simulate, drill or explain the phenomenon. (cited in Egbert, 2005, p. 1) 
WBL supports reading and writing skills by providing opportunities for individualized learning for students at all levels and by letting learners determine authenticity. In individualized learning, learners are expected to be responsible of their own learning, and to be challenged to accomplish tasks of their interest and at their rate, even though, these are performed individually or with peers. The web also help learners make decisions on the materials they want to use or choose for reading and writing, and they are the ones who can determine if what they retrieve is authentic or not, based on their needs or on their interests. That is the flexibility learners have when they access the WWW, thus becoming autonomous learners. Students can also be exposed to extensive reading and writing through conceptualized practice. That is, learners can exchange messages and discuss readings or they can read web-based stories with both audio and video text exposure, and write comments to other on-line reading peers about relevant details. Since writing is closely related to grammar, the WWW provides useful websites to practice specific grammar structures too, especially the ones learners are weak at (Egbert, 2005).

A very useful website that integrates listening, reading and writing skills is NetGrammar (http://www.netgrammar.le.ucr.ac.cr/). NetGrammar is suitable for self-directed learning and also as an extension to regular class work. It was developed with that focus in mind that if students practice new structures in a variety of contexts, it becomes easier for them to internalize and master the many structures of the English language. NetGrammar provides an abundance of both controlled and communicative exercises so that students can bridge the gap between knowing grammatical structures and using them. The design of this website follows certain guidelines that should be considered when web-based courses are created:

First, it is important to contextualize the new content through clear objectives, language functions and notes where new structures are shown in context. This is followed by the second step which is a presentation of the structures (Grammar Focus) with grammar charts and explanations. The third step is the listening part where students hear a variety of short conversations, interviews, storytelling, etc. Fourth, students are engaged in reading. Here, students can find a variety of short authentic passages, mainly newspaper clippings that provide them meaningful information (with pre-reading/while-reading/post-reading activities). In the fifth step students experience writing where students can practice the new structures with the cues provided to them. In addition, learners are engaged in other supplementary tasks and they are directed to web links to enrich their previous practices on grammar, listening, reading and writing. They can also e-mail their writing products to their coach/facilitator and/or other friends. And finally, the six step is the review section, which can 
be used as a self test. Opportunities for asynchronous computer-mediated communication are also possible in NetGrammar when learners share their practices with other learners and the instructor himself/herself. And if questions arise, real-time questioning can occur with the instructor and peers (Quesada, 2000). Indeed, a web-based course can integrate skills meaningfully, and learners can practice with more confidence, feel at ease, have a low affective filter, and obtain personal and academic empowerment in the achievement of the skills. NetGrammar guarantees this integration. Other websites like "Interlink Language Center Reading Lessons" provides practice in extensive reading, speed reading, and science reading for ESL students. "PIZZAZ: People Interested in Zippy and ZAny Zcribbling" is dedicated to provide simple-creative writing and oral storytelling activities with photocopiable handouts to use by students themselves (Egbert, 2005). The strength of these websites is the extensive amount of activities and opportunities students have for enhancing reading, writing, and grammar skills, including the integration of listening and speaking. However, these cannot stand alone. There should be reciprocity with the outside world to promote authentic language learning experiences.

\section{Web-based learning and authenticity}

The Internet should be viewed as an extension of our lives; a tool that allows us to interact with people around the world, a tool that provides for the retrieval of information that is useful for professional and personal development. Through our fingertips, we open a new dimension of knowledge that broadens authentic communication. In second or foreign language learning, the WWW reinforces and expands a greater potential; one that meets specific areas of student needs and/or interests, by building in a degree of choice and negotiation. It also provides ultimate opportunities for increased cross-cultural contact/and awareness, for experienced environments of learner exchange and mentorship in order to gain insights into the language learning difficulties of peers and oneself. There is a degree of flexibility of timetabling language learning activities, too, for students to develop learner autonomy and independence; that is, to learn to manage their own learning. And consequently a very low affective filter with high levels of motivation and self-confidence.

Equally important, Web-based learning fulfills this closeness to the desirability of bringing authentic learning to ESL/EFL classrooms. Whenever an individual, pair or group is assigned web-search tasks on real issues, opportunities for communication and collaboration grow more and more. To illustrate, web-based activities are structured through cooperative learning strategies where each individual has a role to fulfill, a task to accomplish, a problem 
to solve. To reach more meaningful levels of learning, students share the information obtained from the web in class. But, this sharing of information should also have some degree of authenticity in a well-designed web-assisted course. That is, a course that also tells learners that they can become good listeners and responders by incorporating in the assignments evaluation rubrics that classmates complete to promote peer evaluation, or providing handouts where students can take notes that will be included in tests or by requiring peers to synthesize the information heard (Egbert, 2005). Egbert has added that "these techniques, are related, in part, to the condition of autonomy, in that the more choices (autonomy) the students have, the more they need to interact, consult, or negotiate with their team members and class" (p. 55). Through this process, there is a link with traditional classroom settings, indeed, but, this interaction, collaboration, and communication is what brings authenticity to WBL because as students learn and practice communicating without the teacher's presence though the web first, they are able to unknot dependability to teacher direct instruction and direction.

Authenticity through WBL is also fulfilled in creativity and production. Through the net, students are able to create and produce. Egbert (2005) has explained that "creativity implies doing something original, adapting or changing... Working with others often facilitates creativity" (p. 74). He linked it with production by stating that "productivity tools maximize and extend students' ability to create products and to problem-solve; they also expand opportunities for expression which is an important principle for language learning" (p.74). Besides, he has explained that both productivity and creativity tools support second language learners when they are able to construct models, plan, publish, organize and generate materials, collect data and develop and present creative works. Ways of achieving creativity in a Web-based course could be having students create a poster, birthday cards or invitations, ads, class or school newsletters, class announcements, cartoons, classroom diary of poems and stories, and more sophisticated assignments such as interactive web-pages. Egbert has suggested many other types of tasks to enhance creativity and productivity as mazes, catalogs, digital montages (with digital cameras or video cameras) of life of student's country or other countries or any other authentic task. To make it authentic, students are directed to web-links and web-searches to enrich the information they bring to class.

Web-based learning also contributes to the enrichment of metacognitive strategies through trial and error, reflection, and personal involvement. This type of instruction equips the learner with strategies for discovery by questioning, reflecting and researching, necessary for inquiry and problem-solving. Learners are engaged in problem-solving experiences where 
they make accurate observations, or find and organize information as well as predict, synthesize, and use other higher order thinking skills to find solutions (metacognition). Accomplishing these levels of learning help learners remember and understand better, as we learn from this famous Chinese proverb: "I hear and I forget. I see and I remember. I do and I understand". Thus, a Computer-enhanced course is the channel to promote language and content learning which activates critical-thinking skills by way of inquiry and problem-solving activities. Skills such as distinguishing fact from opinion, assessing a reliable web-source, distinguishing relevant from irrelevant information, among others, are triggered in order to make conclusions about something, for example. In a well designed web-course, there are certain steps that have to be met to reach these levels of knowledge (Egbert, 2005):

1) Learners should be able to formulate a question (inquiry question) that has meaning, define the problem and investigate what needs to be investigated to answer it.

2) They should also Investigate by researching; that is, students should be able to organize the information gathered.

3) Students should be engaged in the creation of new ideas or plans of action by applying strategies such as summarizing and interpreting.

4) The participants should have sessions of discussion to get insights on the entire process and share and compare prior knowledge to new knowledge.

5) The students should reach levels of reflection on the entire inquiry process, and think over the decisions and conclusions taken and determine if the results of the inquiry/problem-solving were the ones expected or if further research has to be done.

The new trend in education is engaging students into the construction of their own knowledge and this can be obtained through inquiry-based activities in WBL. The demand is high: lots of responsibility, collaboration and communication is required, real-time participation and investigation is necessary, and authentic focus. The learning of languages also mirrors towards the integration of language into content courses. Incorporating inquiry and problemsolving activities will help learners of all levels (elementary, secondary or tertiary) to relate the second language with the content they are acquiring in their first language, and this is what makes the learning of a language meaningful and authentic. Authenticity is paramount in Web-Based Learning. As the Internet has transformed communication around the world, there is no doubt that it should play a notable role in the foreign language classroom. 


\section{Conclusion}

Since its beginnings, CALL has undergone a number of important stages. First, the behaviorist trend focused on repetitive language exercises and drills and language was seen a mechanical process fostered by the computer. Then, it moved to a communicative approach where the computer was a tool to practice grammar implicitly rather than explicitly, and the target language environment in the computer was more natural, in and out off the screen. Finally, it extrapolated to an integrative approach (multimedia/ Web-based learning) where authenticity and meaningfulness is enhanced by stimulating a learning environment where the four skills are integrated. This new approach generates autonomous learners, facilitating access to authentic materials towards collaborative and individualized learning.

The World Wide Web certainly triggers communication. It is one of the most exciting pedagogical resources in use today. It encompasses a significant, and unlimited amount of educational materials that remodels teaching methodology by incorporating Wed-based learning (Web-based CALL) as a means to shift from traditional teacher-centered classroom to learner-oriented environment. The WWW is indeed an agent of socialization where communication and authentic opportunities of interaction are provided. For this reason, interactivity is the key element in WBL and a crucial strength in the new technological world. It "gives the green light" to learners to become active participants in the learning process for active communication and self-expression in the second language. It also "puts the red light" to English teachers, giving more control to students in class by promoting less teacher talk and enhancing more student talk through computer-mediated situations. Added to this, the unlimited resources of the WWW gives support to the teaching of the four language skills, heightening both individual and collaborative technology-based activities. Web-based learning supports a constructivist model of learning, where students can become more interactive and more involved in their own learning, thereby constructing their own knowledge. The challenges are many, but still the benefits are overwhelming.

\section{REFERENCES}

Alexander, Shirley. (1996). Teaching and learning on the World Wide Web. Retrieved August 29, 2004, from http://sweb95/papers/education2/alexander.html.

Anderson, A. (1996). Predicators of computers Anxiety and performance in information systems. Computers in Human Behaviors. 12 (1): 61-77. 
Baker, W., Hale, T., \& Gifford, B. (1997). Technology in the classroom form theory to practice. Educom Review. 42-50.

Bandura A. (1977). Self-efficacy: Toward a unifying theory of behavior change. Psychological Review. 84: 191-215.

Bandura A. (1986). Social cognitive theory. Englewood Cliffs, NJ: Prentice Hall.

Berge, Zane (1997). Characteristics of online teaching in post-secondary, formal education. Educational Technology. 37 (3): 35-47.

Berge, Z. (2000). New roles for learners and teachers in online higher education. Collaborative Communications Review. McLean, VA: International Teleconferencing Association.

Berge, Z. L., \& Collins, M. P. (1995). Computer-mediated scholarly discussion groups. Computers and Education. 24 (3): 183-189.

Berge, Z. L. \& Collins, M. P. (1995). Computer-mediated communication and the online classroom in distance learning. Computer-Mediated Communication Magazine, 2 (4). Retrieved August 29, 2004, from http://metalab.unc.edu/cmc/mag/1995/apr/berge.html

Buhendwa, Frank M. (1996). Preservice teachers' computer literacy: validation of an instrument to measure self-efficacy for computer-based technologies. (ERIC Document Reproduction Service No. ED404355)

Chen, Li-Ling. (1997). Distance delivery system in terms of pedagogical considerations: A reevaluation. Educational Technology. 37 (4): 34-37.

Chiou, Guey-Fa. (1995). Beliefs and computer-based learning. Educational Technology. 35 (3): 48-52.

Ciardulli, Lisa (1998). Increasing student interaction in the distance learning classroom. Technology Connection. 4 (8): 8-10.

Corbert, R. (1996). Human factors that affect web-based learning environments. Retrieved from September 6, 2004, from http://ccism.pc.athabascau.ca/html/students/rodc/gplhumf.html.

Curriculum guidelines for accreditation of educational computing and technology programs. (1992) (s.f.) International Society for Technology in Education. (ERIC Document Reproduction Service No. ED344583). Retrieved September 2005 from the Retrieved from http://eric.ed.gov/ERICWebPortal/Home.portal? nfpb=true\& pageLabel=RecordDetails \&ERICExtSearch SearchValue 0=ED344583\&ERICExtSearch SearchType 0=eric a ccno\&objectld=0900000b8004fa7a

Edelson, D., Pea, R., and Gordon, D. (1999). Addressing challenges of inquiry-based learning through technology and learning materials design. The Journal of the Learning Sciences. 8 (3 \& 4): 391-450. 
Egbert, J. (2005). CALL Essentials: Principles and Practice in CALL Classrooms. USA: TESOL.

Dickinson, K. (1997). Distance learning on the Internet: testing students using Web forms and the computer gateway interface. TechTrends, 42(2): 43-46.

Dooly, M. A. (2005, March/April). The Internet and language teaching: A sure way to Interculturality. The ESL Magazine: The Information Source for ESL/EFL Professionals Worldwide, 44, (8): 8.

Downing, C. E. \& Rath, G. (1997). The Internet as intranet: moving toward the electronic classroom. Journal of Educational Technology Systems. 25 (3): 273-291.

Duchastel, P. (1997). A Web-based model for university instruction. Journal of EducationalTechnology System. 25 (3): 221-228.

Egbert, J. (2005). CALL Essentials: Principles and Practice in CALL Classrooms. USA: TESOL.

Ellsworth, James B. (1997). Curricular integration of the World Wide Web. TechTrends. 42(2): 24-30.

El-Tigi, M. \& Branch Rober, M. (1997). Designing for interaction, learner control, and feedback during web-based learning. Educational Technology. 37 (3): 23-29.

Evans, B. \& Jones, W. L. (1998). Demonstrating the World Wide Web as an academic research tool. Journal of Computing in Higher Education. 9 (2): 113-134.

Ertmer, P. A. et. al. (1994) Enhancing self-efficacy for computer technologies through the use of positive classroom experiences. Educational Technology Research and Development. 42 (3): 45-62.

Francis, L.J. (1993). Measuring attitude toward computers among undergraduate college students: the affective domain. Computers in Education. 20 (3): 251-255.

Fulton, Kathleen (1998). Learning in a digital age: insights into the issues. The skills students need for technology fluency. T.H.E. Journal. 60-63.

Gaud, W. S. (1999). Assessing the impact of Web courses. Syllabus. 49-50.

The Department of Education. (1996). Getting America's students ready for the 21st century: meeting the technology literacy challenge. (ERIC Document Reproduction Service No. ED398899).

Greene, B. B. (1991). A survey of computer integration into college courses. Educational Technology. 37-47.

Grabinger, R. (1996). Rich environments for active learning. In D. Jonassen (ed.), Handbook of Research for Educational Communications and Technology (pp. 665-692). New York: MacMillan. 
Harris, R. W. (1997). Teaching, learning and information Technology: Attitude towards computers among Hong Kong's faculty. Journal of Computing in Higher Education. 9 (2): 89-114.

Harrison, A. W., \& Rainer, R.K. (1992). The Influence of individual differences on skill in end user computing. Journal of Management Information System. 9 (1): 93-111.

Hartman, V. (1995). Teaching and learning style preferences: Transitions through technology. VCCA Journal. 9 (2): 18-20.

Hashim, Y. (1997). Learner revaluation on the use of collaborative instructional method and instructional media. Journal of Technology System. 25 (4): 363-372.

Henke, H. (2003). Evaluating Web-based Instruction design. Retrieved March 4, 2005 from the World Wide Web: http://scis.nova.edu/ henkeh/story 1.htm

Houle, P. A. (1996). Toward understanding student differences in a computer skills course. Journal of Computing Research. 14 (1): 25-48.

Igbarla, M., \& Chakrabartl, A. (1990). Computer anxiety and attitudes toward computer use. Behavior and Information Technology. 9 (3): 229-241.

Imel, S. (1999). Technological proficiency as a key to job security. Trend and Issues. 6: 3060.

Imprisoned in the Net?: Some promises and dangers of web-based learning. (1997). Retrieved September 15, 2004 from the World Wide Web: http://www.stir.ac.uk/schma/article.html

Jones, T. \& Schieman, E. (1995). Learner involvement: a review of the element of more effective distance education. Canadian Journal of Education Communication. 24 (2): $97-104$.

Johnston, J. H. (1996). Technology: Bring our present and future into the classroom. Schools in the Middle. 5 (3): 27-32.

Jorde-blom, P. (1988). Self-efficacy expectations as a predicator of computer use: a look at early childhood administrators. Computers in the School. 5: 45-63.

Karsten, R., \& Roth, R. M. (1998). The relationship of computer experience and computer self-efficacy to performance in introductory computer literacy courses. Journal of Research on Computing in Education. 31 (1): 14-25.

Kilian, C. (1997). Why teach online. Educom Review. 32 (4): 31-34.

Kinzie, M. B., Delcourt, M. A. B., \& Powers, S. M. (1994). Computer technologies: Attitude and self-efficacy across undergraduate discipline. Research in Higher Education. 35 (6): 745-768. 
Lee Denis, M. S. \& Kahn, B. (1994). The relationship between performance in a computer literacy course and students' prior achievement and knowledge. Journal of Computing Research. 10 (1): 63-77.

Levine, T. \& Donits-Schmidt, S. (1997). Commitment to learning: effects of computer experience, confidence and attitude. Journal of Educational Computing Research. 16 (1): 83-105.

Lucent Technologies Center. (1999). Retrieved October 5, 2005 from the World Wide Web: http://www.lucent.com/cedl/glossary.html.

Maddux, C. D. (1996). The State of the art in web-based learning. Computers in the Schools. 12 (4): 63-71.

McCarthy, M. \& Grabowski, B. (1998). Web-based instruction and learning: analysis and needs assessment summary. Retrieved September 6, 2004 from the World Wide Web: http://www.isoc.org/inet98/proceedings/4c/4c 1.html

McLellan, H. \& McLellen, W. D. (1998). The Internet as a virtual learning community. Journal of Computing in Higher Education. 9 (2). 92-112.

Melara, G. E. (1996). Investigating learning style on different hypertext environments: Hierarchical-like and network-like structures. Journal of Educational Computing Research. 14 (4): 313-328.

Moras, S. (2001). Computer-Assisted Language Learning (CALL) and the Internet. Retrieved April 13, 2005 from the World Wide Web: http://www3.telus.net/linguisticissues/CALL.html

Nalley, R. (1995). Designing computer mediated conferencing into instruction. Computer Mediated Communications and the Online Classroom. 2: 11-23.

Newby, M. \& Fisher, D. (1997). An instrument for assessing the learning environment of a computer laboratory. Journal of Educational Computing Research. 16 (2): 179-190.

The OSEP Online Academy. (1999). Retrieved August 10, 2004 from the World Wide Web: http://onlineacademy.org.

Owston, R. (1997). The teaching Web: A guide to the World Wide Web for all teachers. Retrieved August 28 from the World Wide Web: http://www.edu.yorku.ca/ rowston/chapter.html

Owston, R. D. (1997). The World Wide Web: A Technology to enhance teaching and learning? Educational Research. 26 (2): 27-33.

Perterson, N. S. \& Facemyer, K. C. (1996). The Impact of the Internet on learners and schools. Bulletin. 53-60.

Picciano, A. G. (1998). Developing an asynchronous course model at a large, urban university. Retrieved September 11, 2004 from the World Wide Web: http://www.aln.org/alnweb/journal/vol issue1/picciano.html 
The President's educational technology initiative. Retrieved September 15, 2004 from the World Wide Web: http://www.whithouse.org/WH/EOP/edtech/html/edtech f.html

Price, R. (1996). A Model for the on-line college level guided study course. Tech Trends. 41 (6): 39-43.

Polyson, S., Saltzberg, S., \& Godwin-Jones, R. (1996). A practical guide to teaching with the World Wide Web. Syllabus. 10: 12-16.

Quesada, A. (2000). Using the Web to Practice and Learn Grammar: ESL Students' Perspectives. Mosaic: A journal for Language Teachers. 8(21): 6-9, Ontario, Canada.

Rakers, G. C. (1996). Using the Internet as a tool in a resource-based learning environment. Educational Technology, 36 (5): 52-56.

Reed, W. M. \& Oughton, J. W. (1997). Computer experience and interval-based hypermedia navigation. Journal of Research on Computing in Education. 30 (1): 38-52.

Ritchie, D. C. \& Hoffman, B. (1996). Instruction and the Internet. Retrieved April 5, 2005 from the World Wide Web: http://edweb.sdsu.edu/c/rit/learningtree/DCD/WWWInstrdesign/References.html

Roberts, N., B., G., \& Barowy, W. (1996). The dynamics of learning in a computer simulation environment. Journal of Science Teacher Education, 7 (1): 41-58.

Royer, R. (1997). Teaching on the Internet: Creating a collaborative project. Learning and leading with Technology, 25 (3): 6-11.

Rowntree, D. (1995). Teaching and learning online: A correspondence education for the 21st Century? British Journal of Education Technology, 26 (3): 205-215.

Russo, T. C., Campell, S., Henry, M.P. \& Kosinar, P. (1999). An online graduate class in communication technology: outcomes and lessons learned. Electronic Journal of Communication. Retrieved August 18, 2004 from the World Wide Web: http://www.cios.org/www/ejc/v9n199.htm\#Cours

Schlough, S., \& Bhuripanyo, S. (1998). The development of evaluation of the Internet delivery of the course task analysis. Distance Education. 99-102.

Selwyn, N. (1997). Students' attitude toward computers: validation of a computer attitude scale for 16-19 education. Computer and Education, 28 (1): 35-41.

Smith, J. M. (1994). The effects of education on computer self-efficacy. Journal of Industrial Teacher Education. 31 (3): 51-65.

Talab, R. S. \& Newhouse, B. (1993). Self-efficacy, performance variables and distance learning facilitator technology adoption: support for the teacher needs hierarchy. (ERIC Document Reproduction Service No.ED362207). 
Topper, A. G., Gillinghan, M. G., Ellefson, N. C., \& Worthington, V. L. (1997). Teacher professional development on the World Wide Web: The LETSNet web Site and teacher Learning. Journal of Computing in Teacher Education. 13 (4): 25-33.

Warschauer, M \& Kern, R. (2005). Network-based language teaching: Concepts and Practice. Cambridge: Cambridge University Press.

Warschauer, M., Shetzer, H. \& Meloni, C (2002). Internet for English Teaching. USA: TESOL.

Williams, A. E. (1996). Integrating courses with the Internet: preparing the teacher as well as the learner. (ERIC Document Reproduction Service No. ED 405839)

Wise, A. E. (1995). Raising expectations for technology in teacher education. Quality in Teaching. 5 (1): 1-2.

Wood, R. E. (1999). Beyond the electronic reserve shelf pedagogical possibilities and resources in Web-enhanced courses. Syllabus. 54-56.

Zack, M. (1995). Using electronic messaging to improve the quality of instruction. Journal of Education for Business. 70 (4): 202-206.

Zhang, Y., \& Espinoza, S. (1997). Affiliations of computer self-efficacy and attitudes with need for learning computer skills. Journal of Educational Computing Research. 17 (4): 371-383.

Zimmerman, B. J. (1995). Self-efficacy and educational development. Self-efficacy in Changing Societies. Cambridge: Cambridge University Press. 